\title{
Left or Right Hemisphere? A Novel Answer to the Old Question of Lateralization by Introducing IRL (Individualistic Relativistic Lateralization)
}

\author{
Parviz Birjandi \\ Department of English Language Teaching, Science and Research Branch, Islamic Azad University, Tehran, Iran \\ Seyyed Hassan Seyyedrezaei \\ Department of English Language Teaching, Aliabad Katoul Branch, Islamic Azad University, Aliabad Katoul, Iran \\ Email: teflsh@yahoo.com
}

\begin{abstract}
Although lateralization for language functions gives the sheer authority of language centers and control to the left hemisphere, there is a strong debate among the specialists regarding which hemisphere has the responsibility for language. There is not a complete meeting ground among the scholars on the roles of each hemisphere in language processes either. The recent studies including the advanced technologies such as neuroimaging, Positron-emission Tomography (PET) and functional MRI come up with contradictory findings that do not support the long time claim of left hemisphere dominance. Generally, this paper aims at finding a novel answer to the old question of lateralization in language acquisition. More particularly, first it attempts to review the latest researches to see the role of left and right hemispheres in language processes. Second, it introduces a novel version of lateralization as IRL (Individualistic Relativistic Lateralization) that rejects the notion of "left-brain only" and "right-brain only" person and functioning and accordingly rejects also the absolute generalizeable perspective to lateralization and localization.
\end{abstract}

Index Terms - left hemisphere, right hemisphere, lateralization, IRL

The history of the role of brain in language learning is as old as ancient times. In Ahlsen`s (2006), the first reference to the brain as the center of language dates back to $3500 \mathrm{BC}$ and crystallization of all probing into knowing the brain as such a center in neurolinguistics theories emerged in the $19^{\text {th }}$ century when neurolinguistics is introduced by Broca's (1861) theory that language is located in the left hemisphere. Neurolinguistics studies the relation of language and communication to different aspects of brain function. It tries to know how the brain understands and produces language and communication. According to Ahlsen (2006), it is also an interdisciplinary field with the fields of linguistics, neuroanatomy, neurology, philosophy, psychology, speech pathology, and computer science reflecting on it which all make the field rather immense and mighty. Kopke (2004) defines it as the relation of language and communication to different aspects of brain function, that is, it attempts to explore how the brain comprehends and produces language and communication. In fact, neurolinguistics tries to combine theory from neurology/ neurophysiology (how the brain is structured and how it functions) with linguistic theory (how language is structured and how it functions). According to Kopke (2004), neurolinguistics is a branch of Cognitive Neuroscience that, on its turn, together with Systemic, Movement, Sensory and Cellular, is a branch of a larger domain named the Neurosciences.

There have been different attempts by both language specialists and neurologists for over a century to understand how the brain learns, stores, and processes language but it proved to be a demanding onerous task because there are no animals that have symbol systems as rich as language. Therefore, for a long time, information about how the brain processed language could only come from the study of the effects on language of neurological disease in pathologies caused by various forms of brain injury. The high complexity of the brain and its functions on one hand and the complexity of the language itself and its functions on the other hand have led to different views about the relation between brain and language. Ahlsen (2006), for instance, refers to five views that are introduced in brief as follows:

Localism: This view tires to locate different centers in the brain which are responsible for different language functions and claims that they are mostly located in the cortex (Ahlsen, 2006) which are either two or more equally important parts for a function or a part is super ordinate to other parts regarding a function. Localists like Broca and Gall define aphasia as trauma to a language function center.

Associationism: This view situates language functions in connections of different areas of the brain's cortex. Thus based on this view, Ahlsen (2006) defines aphasia as a broken connection between the centers needed for a language function. Among the supporters of this view are Wernicke and Geschwind.

Dynamic localization of function: it assumes that functional systems of localized subfunctions perform language functions. Such systems are dynamic, and thus they can be reorganized during language development or after brain damage. 
Holistic: it views language functions as handled by differing parts of the brain working together. According to Ahlsen (2006), holism is the opinion that the brain works as a whole, at least to accomplish higher functions. The cortex is said to handle, for example, higher cognitive functions, symbolic thinking, intelligence or abstraction. To advocates of holism, who are also called cognitivists, aphasia is a sign of general cognitive loss, not a specific language loss.

Evolution-based: this refers to those theories that deal with language and brain evolution over time and consider the difference between children's and adults' performances on language functions.

"Unitarism and Equipotentiality" is another view discussed by Jacyna (1999). According to Jacyna (1999), "unitarism" refers to one unitary function of the brain, the view that the soul is one and cannot be divided, and "equipotentiality", means that all parts of the cortex have the same functional potential and that the size of a brain lesion determines the extent of the aphasia.

As a hot topic in neurolinguistics, lateralization has received a lot of attention in the literature. For example, Richards and Schmidt (2002) define lateralization as "the development of control over different functions in different parts of the brain" (p.68). Pinker (1994) also defines lateralization as the most striking anatomical characteristic of the human brain by which it is divided into two hemispheres, so that it has two of almost every structure: one on the left side and one on the right. He goes on to say that these paired structures are not exactly are symmetrical and differ in their size, form, and function. As the brain develops, it is thought that different bodily functions (e.g. speech, hearing, sensations, actions) are gradually brought under the control of different areas of the brain. According to Lust (2006), recent investigations have focused on brain function in normal subjects while they perform tasks that involve language. Language lateralization which is also known as the Cerebral Functional Asymmetry, according to Paradis (1985), refers to the condition wherein one hemisphere rather than the other is relatively more active during performing a specific task. Although some scholars have considered left-hemisphere as the key organ in the process of language acquisition, the observations made during a great deal of studies have resulted in the view that the right hemisphere is necessary for language processing and that trauma to this side of the brain could result in severe linguistic discrepancies. The two most lateralized functions in the human brain are motor control and language. When a function is lateralized, this often means that one side of the brain exerts more control over this function than what the other does. The side that exerts more control is often called the "dominant hemisphere" for this function

The curious search for the question "What is the "dominant" hemisphere for language?" was first answered by Broca (1861) who considered "left hemisphere" involving in speaking. Broca (1861), a French neurosurgeon, examined the brain of a recently deceased patient who had an unusual disorder. He studied several other patients, all of whom had language deficits along with lesions in their left frontal hemisphere. Accordingly, he concludes that the left hemisphere controls speaking. Ten years later, Wernicke, a German neurologist, discovered another part of the brain, this one involved in understanding language, in the posterior portion of the left temporal lobe.

Unlike Broca`s and Wernicke`s assertion on the left hemisphere dominance, there are some who believe otherwise. For instance, Paradis (1990) emphasizes the role of right hemisphere in L1 acquisition. Ellis (2008) also cites Albert and Obler's (1978) suggesting that bilinguals show a major right hemisphere contribution as well. Ahlsen (2006) also reports the right hemisphere as more involved in L2 processing than in L1 processing. Zatorre (1989) refers to a number of studies that point out the greater involvement of the right hemisphere in bilinguals than in monolinguals too.

The advent and use of advanced technologies such as neuroimaging, Positron-emission Tomography (PET) and functional MRI in neurolinguistic studies have revealed some other facts that support right hemisphere involvement in language functions. For instance, Dehaene et al. (1997) are among those that Birdsong (2006) cites to report such right hemisphere activation through Positron-emission Tomography (PET) and functional MRI studies. Recently, a lot of research has been done using neuroimaging techniques which have provided a great deal of insight into the neural representation of second languages. Kim, Relkin, and Hirsch (1997, cited in Birdsong, 2006) also conclude that the native and second languages show different patterns of neural activation for subjects who had acquired proficiency in the L2 after 10 years of age, whereas the patterns are comparable in childhood bilinguals. The results of this study are interesting in that they show neural evidence that L2 acquisition in adults differs greatly than that in children. Accordingly, it is understood that a lot of research has been done to shed light on the neural processes involved in the brain in acquiring L1 and L2.

The old belief of "left hemisphere dominance" and localization is also under the question in L2 and bilingual studies (e.g. Ahlsen, 2006; Ellis, 2008; Paradi, 2004; Zatorre, 1989). Many researchers have dealt with this issue interested in finding out whether there is any possible different cerebral organization for each language in the people who know two languages. Grosjean (1989) presents two views about bilingualism-the monolingual or fractional view which holds that the bilingual is two monolinguals in one person, and the bilingual or holistic view which states that the coexistence of two languages in the bilingual has produced a unique and specific speaker-hearer. Grosjean (1985) maintains that the monolingual view of bilingualism has created some negative consequences. The first is that bilinguals (which we define as those people who use two or more languages in their everyday lives) have usually been described and evaluated in terms of the fluency and balance they have in their two languages. A second consequence of the monolingual view is that language skills in bilinguals have almost always been appraised in terms of monolingual standards. The tests used with bilinguals are often quite simply the tests employed with the monolinguals of the two corresponding language groups. As another negative consequence of the monolingual view, we can refer to the point that bilinguals rarely 
evaluate their language competencies as adequate. They often consider and encourage the monolingual view and, as a result, criticize their own language competence. They criticize the lateralization discussion into which hemisphere handles which language because they see it as very simplistic. They reject L2-specific areas of activation mentioning that different languages involve different circuits but in the same language areas of the brain. Hull (2003) states that the right hemisphere is responsible for the control of semantic and pragmatic aspects of language. Obler (cited in Henningsen, 2002) shows some evidence for right hemisphere participation in early stages of first and second language acquisition. The right side of brain is more visual and processes intuitively, holistically, and randomly. These investigations have led to interesting and sometimes differing results. Therefore, it seems reasonable to suggest that more caution should be taken before confirming the existence of difference between the neural representation of the L1 and L2 and if so the causes of such differences have to be accounted for through meticulous research.

Herrmann (1990) draws on the work of Sperry and developed the theory of brain dominance where people develop a dominant mode of thinking preference. These can range from an analytical "left brain" approach to "right brain" approaches involving pattern matching and intuitive understanding. These preferences have their roots in our genetic makeup and how it affects our underlying cognitive capabilities. As we develop we tend to respond with our strongest abilities as these lead to quicker short-term rewards. This can create a positive feedback system that will strengthen those abilities. Eventually this can lead to a powerful preference for one style over the other and a dislike and discomfort for other modes of thinking.

There are also reservations regarding the correlation between handedness and language lateralization. It has been reported that such a correlation does exist, but it is not perfect. In the vast majority of right-handed people, language abilities are localized in the left hemisphere. But contrary to what you might expect, the opposite is not true among lefthanded people, for whom the picture is less clear. Many left-handed people show a specialization for language in the left hemisphere, but some show one in the right, while for still others, both hemispheres contribute just about equally to language.

The controversy also exists about the correlation between sex and lateralization. It was believed that women were more left hemisphere bounded than men but in a meta-analysis, Voyger (1996), for example, evaluated the results of monolingual and bilingual studies of lateralization in regard to sex differences as an independent variable influencing laterality. He came to the conclusion that sex-dependent laterality was most noticeable in the visual and auditory modalities. He found that men showed generally more left hemisphere lateralization than women.

The literature also reports an ongoing debate among the specialists regarding the relationship between lateralization and the critical period. Lennenberg (1967) believes that brain lateralization is complete at puberty and this is the major reason for the difficulty of post-adolescent language acquisitions. His idea of the coincidence of puberty (the end of the critical age) and the completion of lateralization has been challenged by many including Krashen (1973) who believes the process to be completed well before puberty. Several scholars have suggested "Multiple Critical Periods" saying that since the different components of language- phonology, morphology, syntax, lexicon, and pragmatics are acquired relatively independently of each other, their development might follow different timetables, pointing to the possible existence of multiple critical periods for a person. Knudson (2004, cited in Dornyei, 2009) argues that language depends on a wide range of specialized sensory, motor, and cognitive skills that involve many neural networks and structures, and they are shaped differently by experience. It is generally assumed in the linguistic community that children learn second languages more easily and quickly than adults. This difference in ability has been traced back to the existence of "sensitive (or critical) period," which ends at around 8-10 years of age. It is thought that the pre-mature brain has a higher degree of neural plasticity than the post-mature brain and that this directly relates to the neural bases of second language acquisition. However, there is great disagreement about the extent to which adult second language learners are inhibited due to these neural differences.

There has been much interest in the similarity or differences of brain processes in L1 and L2 acquisition. Since the brain is assumed to be modular, there has been debate about whether there are separate modules for the L1 and L2. As Ellis (2008) states if there is a specific faculty for the language, then the neurobiological basis is the same for the acquisition of these two processes. But if not, it must be assumed that they are different.

Another area of debate lies in the differences between lateralization in acquisition of a second language and that of the first language acquisition. Given that the human brain continues to develop until puberty, they propose that a language that is acquired after brain maturation is complete, may show different neural mediation than that characterizing the language acquired while the brain is still developing. They have tried to trace the differences in second language laterality. Albert and Obler's (1978 cited in Ellis, 2008) study suggests that a bilingual brain has a different organization for L2 than L1. Galloway (1980 cited in Ellis, 2008) reports that 98\% of aphasias in monolinguals is due to left hemisphere injuries and just $2 \%$ to right hemisphere injuries where the same ratio in bilinguals changes to be $85 \%$ and $15 \%$. Albert and Obler's (cited in Ellis, 2008, p. 744) early work on hemispheric differentiation indicated that bilinguals were less hemispheric dominant than monolinguals. But this idea has been much criticized by researchers like Paradis (cited in Ellis, 2008) who came to the conclusion that both the L1and the L2 are served by the same language areas but involve different circuits within these areas. 
The complexity of the issue increases when the studies show that a couple of potential moderating factors affect the nature of cerebral lateralization such as Sex, Task Demands and Complexity of Language, Distance/Relationship between First and Second Languages, and Language Environment. These factors will be discussed briefly as follows:

Sex

In a meta-analysis, Voyger (1996, cited in Paradis, 2000) evaluates the results of monolingual and bilingual studies of lateralization with regard to sex differences as an independent variable affecting laterality. Shanon (1982), on the other hand, reports that bilingual men show more right hemisphere involvement for word processing in comparison with women.

Task Demands and Complexity of Language

The number and types of tasks used in laterality studies is another source of variation in the reported results from the previous studies. The tasks used in such studies are varied from single word recall to translation. According to Grosjean (1989), it has been suggested that brain involvement during sentence level processing differs depending upon the complexity of sentence structure. When sentences contained semantically rich word clauses, there was an increased right hemisphere $(\mathrm{RH})$ activation, but words in isolation caused increased left hemisphere (LH) involvement (Schumann, et al, 2004).

\section{Distance/Relationship between First and Second Languages}

Linguistic distance/relationship between L1 and L2 as a moderating factor of cerebral lateralization in bilinguals has been investigated by many studies. The findings of such studies reveal that languages that are structurally very dissimilar, tend to show greater differences in language laterality than those languages which are structurally related.

\section{Language Environment}

According to Ulman (2001), current models of language representations for language in bilinguals assume that there are functional differences between the L1 and L2; some theorists have suggested that environmental context in which first and second languages are used may lead to a different pattern of organization.

The abovementioned controversies well show that in spite of the long piles of literature on neurolinguistics and lateralization, there are still a lot of conspicuous debates among the specialists in various questions on laterlization. Ideas greatly differ regarding different patterns of activity traced in different areas of the brain while the issue of lateralization seems to be still under debate. Here are some points why the findings contradict each other to this extend:

A. The techniques of inquiry may not be very illuminating. Paradis (2004, cited in Gabrys-Barker, 2010) criticizes neuroimaging for a lack of linguistic sophistication and provides these reasons for it:

(1) The tasks are often nonlinguistic tasks (i.e. not part of the natural use of language) and hence do not involve the implicit procedural computations that underlie the processing of a verbal message either in comprehension or production.

(2) The selected stimuli often do not target components of language function and hence are not language relevant.

(3) Sometimes linguistic material is used, but in a nonlinguistic context, and thus it does not reveal any kind of language processing.

(4) Researchers do not differentiate between implicit and explicit components of language and often generalize from words (whose form and meaning are supported by declarative memory) to language (whose implicit system- phonology, morphology and syntax- is supported by procedural memory).

B. Different experimental paradigms have been used by different research groups and not the same selection criteria have been applied for the inclusion of the subjects in experiments. That is why the findings on age factor, $\mathrm{CPH}$ and localization are inconsistent (Van Den Noorth et al., 2010).

All of the controversies and inconsistencies of the findings discussed above are natural to some extent as both language and brain are too complex to be described and formulated simply. Given everyone enjoys a unique brain and a unique language; we should eschew form any generalizations in neurolinguistic studies including lateralization. Instead, the idea of lateralization should be studied qualitatively for every human being through a relativistic lens. This paper suggests IRL (individualized relativistic lateralization) that avoids any generalizations and accentuates the unique process of lateralization for human learning.

Individualized relativistic lateralization (IRL)

IRL can be defined as the development of control over different functions in different parts of the everyone`s brain that are not necessarily the same parts in the brains for all the people and these parts may be open to adopt different functions for different people. It is individualized as it is unique to everyone and may differ from one to one and it is relativistic as we cannot assign fixed roles for each parts for language processes given the contradictory results in the literature. All the studies validate the lateralization process and its role in language functions but IRL helps us to eschew big claims and generalizations regarding such a complex process (language) in the most sophisticated part of human (brain).

\section{Conclusion}

The absolute looks supported by the past studies regarding the lateralization and language functions that were mostly on the same page for the left hemisphere dominance and localization of language centers were to a large extent subject to doubts and debates by different studies. This controversy stems from two important reasons: the complexity of the brain and the complexity of the language itself. The too much debate on lateralization studies and the role of 
hemispheres in language functions are so abundant that we should eschew the absolute generalizeable perspective to the aforementioned areas. In Caplan`s (1995) words, "Our dominance is a preference, not an absolute" (p.303). While functions are lateralized, these lateralizations are functional trends, which differ across individuals and specific function. No one is a "left-brain only" or "right-brain only" person. Even within various language functions (e.g., semantics, syntax, prosody), degree (and even hemisphere) of dominance may differ. In the end, due to the uniqueness of human brain and language everyone enjoys, IRL (individualized relativistic lateralization) is suggested that avoids any generalizations and accentuates the unique process of lateralization for human learning.

\section{REFERENCES}

[1] Ahlsen, E. (2006). Introduction to neurolinguistics. Amesterdam: John Benjamins.

[2] Birdsong, D. (2006). Age and second language acquisition and processing. In M. Gullberg \& P. Indefrey (Eds.), The cognitive neuroscience of second language acquisition (pp. 9-49). USA: Blackwell Publishing.

[3] Broca, P. (1861). Sur le principe des localisations cérébrales. Bulletin de la Société d'Anthropologie tome, 2,190-204.

[4] Caplan, D. (1995). Language and the brain. The Harward Mahoney Neuroscience Institute Letter on the Brain, 4(4), $302-313$.

[5] Dornyei, Z. (2009). The psychology of second language acquisition. Oxford: Oxford University Press.

[6] Ellis, R. (2008). The study of second language acquisition $\left(2^{\text {nd }}\right.$ ed). Oxford: Oxford University Press.

[7] Gabrys-Barker, D. (2010). Emotion versus cognition, or what psycho and neurolinguistics tell us about affectivity in second language acquisition. In J. Arabski \& A. Wojtaszek (Eds), Neurolinguistic and psycholinguistic perspectives on SLA (pp. 4463). Bristol, UK: Multilingual Matters.

[8] Grosjean, F. (1989). Neurologists beware! The bilingual is not two monolinguals in one person. Brain and Language, $36,3-5$.

[9] Henningsen, H. (2002). Language lateralization in healthy right-handers. Oxford: Oxford University Press.

[10] Herrmann, N. (1990). The creative brain. North Carolina: Lake Lure.

[11] Hull, R. G. (2003). How does bilingualism matter? A meta-analytic tale of two hemispheres. Doctoral Dissertation. Texas A \& M University.

[12] Jacyna, S. (1999). Essays in the history of neurolingisyics. Brain and Language, 69, 1-3.

[13] Kopke, B. (2004). Neurolinguistic aspects of attrition. Journal of Neurolinguistics, 17, 3- 30.

[14] Krashen, S. D. (1973). Lateralization, language learning, and the critical period: Some new evidence. Language Learning, 23(1), 63-74.

[15] Lennenberg, E. (1967). Biological foundations of language. New York: John Wiley.

[16] Lust, B. (2006). Child language: Acquisition \& growth. Cambridge: Cambridge University Press.

[17] Paradis, M. (1985). On the representation of two languages in one brain. Language Sciences, 7(1), 1-39.

[18] Paradis, M. (1990). Language lateralization in bilinguals: Enough already. Brain and Language, 39, 576-586.

[19] Paradis, M. (2000). The neurolinguistics of bilingualism in the Next Decades. Brain and Language, 71, 178-180.

[20] Pinker, S. (1994). The language instinct. London: Penguin.

[21] Richards, J. C., \& Schmidt, R. (2002). Longman dictionary of language teaching and applied linguistics ( $3^{\text {rd }}$ ed.). London: Pearson educated limited.

[22] Schumann, J. H., Crowell, S., Jones, N. E., Lee, N., \& Schuchert, S. A., Lee, A. W. (2004). The Neurobiology of learning perspectives from second language acquisition. New Jersey: Lawrence Erlbaum Associates, Inc.

[23] Shanon, B. (1982). Lateralization effects in the perception of Hebrew and English words. Brain and Language, 17, 107-123.

[24] Ulman, M. (2001). The neural basis of lexical and grammar in first and second language: the declardative/procedural model. Bilingualism, 4(2), 105-122.

[25] Van Den Noort, M., Bosch, P., Hadzibeganovic, T., Mondt, K., Haverkort, M., \& Hugdahl, K. (2010). Identifying the neural substrates of second language acquisition: What is the contribution from functional and structural MRI? In J. Arabski \& A. Wojtaszek (Eds), Neurolinguistic and psycholinguistic perspectives on SLA (pp. 3-16). Bristol, UK: Multilingual Matters.

[26] Voyger, D. (1996). On the magnetic laterality effects and sex differences in functional lateralities. Laterality, 1(1), 51-83.

[27] Zatorre, R. J. (1989). On the representation of multiple languages in the brain: Old problems and new directions. Brain and Language, 36, 127-147.

Parviz Birjandi is a full professor holding a Ph.D. in English education; minor: Research methods and statistics from the University of Colorado. He is the former Dean of the College of Foreign Languages and Persian Literature in the Islamic Azad University, Science and Research Branch. He has published a couple of articles in the area of TEFL and he is the author of English textbooks used nationwide.

Seyyed Hassan Seyyedrezaei is a Ph.D. student in ELT at Islamic Azad University, Tehran, Science and Research Branch. He is a faculty member at Islamic Azad University, Aliabad Katoul Branch. He is the author of a number of articles and textbooks in TEFL and presented dozens of articles in different conferences throughout the world. 